\title{
Digital Generative Tools for Restitution and Mediation for Cultural Heritage
}

\author{
Renato Saleri \\ MAP UMR 3495 CNRS/MC \\ ENSAL, 3 rue Maurice Audin, 69512 \\ Vaulx-en-Velin Cedex, France \\ renato.saleri@lyon.archi.fr
}

\begin{abstract}
Computer aided-design (CAD) tools should be able to assist the former exploration that leads the entire design process. However, current software often calls an immediate actualization of geometrical intentions by forcing the user with pre-set intentional clusters - geometric primitives, textural resources, design procedures etc. - often uncompromising, with poor intuitive feedback and generally restraining imagination spreadout: most CAD software act like over-equipped handdrafting assistants, assuming the maturity of the designer as much as the maturity of the project itself. What we aim to achieve is a computer-assisted generation process of architectural and urban plausible geometries. These self-generated objects are intended to act like "imagination enhancers" serving conceptual exploration of architectural design or providing credible 3D environments in given historical context. Next, this "pr-object" could not only be the ponderated completion of a pluridisciplinaric integration process but, in an autonomous evolution Darwinian paradigm, the actualization of the most performant genotype, or like Celestino Soddu says, a generative project is a concept software that works producing three-dimensional unique events as possible and manifold expressions of the generating idea identified by the designer as a subjective proposal of a possible world. Some of the research tasks depicted hereby take advantage of some generative methods developed within the MAP aria research team. They are able to quickly produce architectural and urban geometric simulations for contextual or historical restitutions. In the case of the Portus project, which required 3D modelling and rendering of the Ostia harbour complex at different times, generative design quickly established itself as a solution for dealing with the heterogeneity of the available scientific hypotheses.
\end{abstract}

Architectural heritage. 3D modelling. Digital generative tools. Formal grammars.

\section{INTRODUCTION}

Computer-aided design tools have been used in architecture and design offices for more than 30 years. It must be said that, from the beginning, they have behaved more like over-equipped drawing tools than as true supports for the creative process. However, in recent years, additional modules (plugins or dedicated libraries) make it possible to enrich the software environments already implemented in creative agencies: whether in the field of design, urban planning or architecture, these tools can generate and optimise on demand an infinite number of formal or conceptual solutions whose feasibility or effectiveness in terms of input constraints will be evaluated, for example, by bioinspired processes.

In the field of heritage, ancient monumental political or religious groups have often come to us. This is not the case for the "connective" urban fabric, whose importance maybe less relevant has certainly been the cause of successive profound transformations and of which only traces remain today. It is in this context that we were very early interested in the generative tools that can be involved in 3D restitution processes for architectural or urban ensembles at a given historical period.

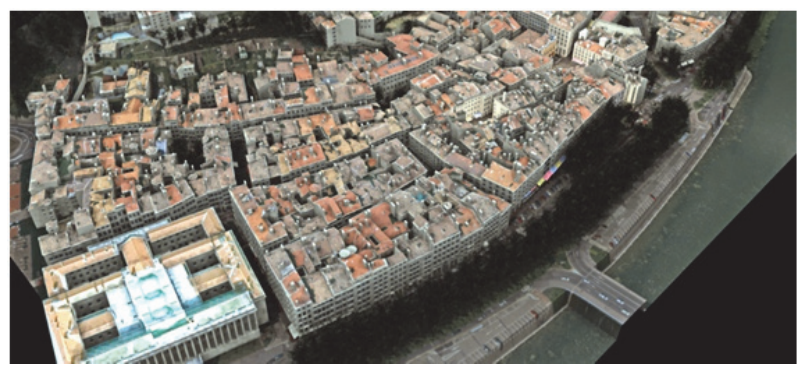

Figure 1: The "Vieux Lyon" district reconstruction (2004). 
Whether for the restoration of the ancient city of Vienne (France), to show the inhabited slopes of the Fourvière hill during the time of Lugdunum or the historic urban fabric of the "Vieux Lyon" district (Figure 1), the generative tools are based on current knowledge of the architectural, constructive or stylistic constants of the time and are aligned with the road or masonry routes that have survived: they thus make it possible to quickly produce plausible 3D images of squares, streets or buildings during the period of interest (Saleri 2004).

As part of the exhibition "Claude, un empereur au destin particulier", presented at the Musée des beaux arts de Lyon, the laboratory had the opportunity to exploit the software tools developed so far by putting them at the service of a major project: the 3D restitution of the Ostia harbour complex at the time of Trajan as well as the successive transformations brought by the Emperor Claude during his lifetime.

The confrontation with the particular case of the Trajan period vernacular habitat has made it possible to question in depth the structure of the rule bases used to automatically generate plausible architectural configurations for this particular period. This experiment raised once again the question of the discontinuity of the generative models used, which will have to be applied differently not only according to the scale (bay, facade, building, block, district etc.) but also according to the nature of the objects to be represented or the knowledge available about them (Duarte, 2001). In our case, this may concern vernacular islets in the working class districts, residential buildings whose influence concerns the whole block or even monuments or elements built during excavations or subject to divergent historical conjectures. This paper presents the methods and results obtained during this new experiment and questions the possibilities of a different generative approaches that could be applied to the specific case of historical and heritage architecture.

\section{RELATED WORKS}

Procedural or parametric modeling tools are now widely used to structure 3D information (Müller et al., 2007, 2006). Many existing applications exploit particular formalisms - rule bases or recursive formal grammars such as L-Systems (Saleri 2008) - explore stochastic geometric tools (Saleri 2003) or rely on bio-inspired formalisms such as genetic algorithms or neural networks (Fons et al. 2009). Others are implemented in dedicated frameworks such as cityEngine using specific languages such as Computer Generated Architecture (CGA) Shape or Generative Modeling Language (GML) (Haegler et al. 2009) capable of producing extremely convincing urban simulacra (Wonka et al. 2003). Some approaches address the theme of ecodesign integrated with the architect's tools in the phase between architectural or urban design (Marin et al. 2012; Chevrier 2015). Finally, others apply operational approaches capable of simplifying the topology of heritage objects recorded by photogrammetry or lasergrammetry by exploiting the preliminary geometric knowledge of the objects to be recorded (Jacquot et al. 2013); these methods apply only to particularly well preserved heritage objects: this is the case, for example, of the study under way at the MAP laboratory on the relief plans of French fortified towns from the 17th and 18th centuries, which have reached a state of conservation that is often exceptional (Chevrier et al. 2015; Gros et al. 2019). However, it happens that the very specific needs of a historical restitution require the implementation (design) of a dedicated tool using a specific pipeline capable of responding very precisely to the requests formulated by archaeologists or historians. In this article we will briefly explain the principles implemented during the project to restore Portus, the famous port of Ostia during antiquity, presented during an exhibition at the Museum of Fine Arts in Lyon and which will soon be the subject of a new exhibition at the Ara Pacis Museum in Rome.

\section{GENERATIVE DESIGN FOR HERITAGE}

The creation of multiscale urban simulacra can respond to a need to represent vanished urban realities of which only traces can be found today: on the ground there are many buried remains, witnesses of built routes eroded by the incessant succession of urban transformations responding to the changing uses of social and individual practices. The following sedimentation - often borrowing from the past the available materials already shaped for constructive use - deeply stirs the urban fabric. Fortunately, there is no shortage of first-person accounts of the past, which provide a number of interpretations that are constantly being updated, making it possible to reproduce with relative precision - in view of the often "personalised" nature of the interpretation or the desire to glorify an event or character - the sensitive epidermis of a historical reality built or experienced (2D representations, texts, models (relief plans, etc.). Almost always, urban redesigns are profoundly heterogeneous and challenge historical strata in unequal proportions in planimetry as well as altimetry. Of course, the built heritage is constantly being reinvented, a process of restitution, however meticulous it may appear, will only aim to reproduce a small plot of it, located in space and identified over time. The validity of a visual reconstruction will then depend on the reliability of existing knowledge. In the same sector, 
some areas will have been excavated, surveyed and documented while others will be ignored or inaccessible: this means that we will represent in a homogeneous way knowledge whose scientific validity cannot be guaranteed to be of the same level (Schinko et al. 2010). The previous documents to which one can have access do not provide information on the validity of the available information, which can be very incomplete locally: in order to show a little-known reality, the scientific validity of the entire restitution is compromised. Restitution hypotheses may thus tend to standardise the architectural expression of urban reconstruction by exploiting a set of rules whose morpho-stylistic scope belongs only to a historically targeted stratum, as if the historical sediments applied homogeneously to an entire sector. To be credible, a restitution must then be able to bend to the constructive and expressive variables of a given period, in the light of the knowledge available today. It must also be able to be modified at the request, if the information held about it is significantly challenged. The digital tools developed and tested by the laboratory are designed to guarantee the traceability of the geometric transformations in 2D and 3D produced and to allow, as far as possible, any subsequent modifications. Admittedly, we cannot guarantee the durability of a proprietary file format or the duration of a commercial product on our own scale (the demonstrators made barely fifteen years ago in VRML or Virtools@ are today practically unusable).

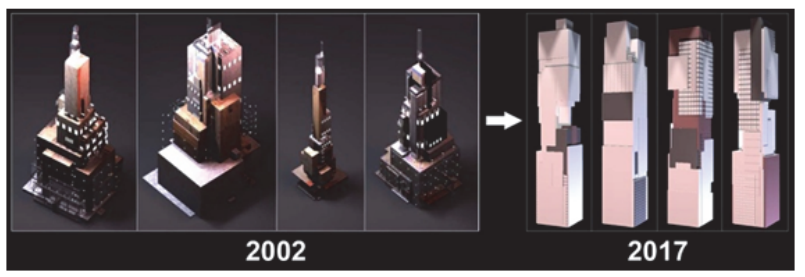

Figure 2: The same generative protocol put to test in 2002 and in 2017 with recent technologies. The 2017 data set was real-time generated and rendered.

On the other hand, we can move upstream towards web-based environments or open source formats and guarantee as much as possible in the workflows developed an automation of interoperable processes: this is how, during the first architecture biennial of the City of Lyon, in 2017, we were able to reuse the generative tools developed in $2002-2003$ by using the same software classes and using the same data structures (Figure 2). With such a tool, we could partly put aside the books of the Babel library by J.L. Borges: the very modest installation set up by the laboratory during the Lyon Architecture Biennale of 2017 generated nearly 300,000 architectones - most of them anonymous and erased from the memory of the computer as soon as another took its place -24 hours a day, during the 5 days of the event...

\section{EXPERIMENTING WITH GENERATIVE PROTOCOLS}

The parametric construction of architectural objects does not follow a constructive logic, at least not in its operational expression. Rather, it follows a preliminary decomposition of semantically identifiable architectural entities - naturally responding to the lexical scope of the expressed term - and classifiable by constructive click: the cliques concerned group together homogeneous elements from the descriptive point of view but may incorporate topological descriptors that will allow to nuance their nature. The difficulty consists in defining a conceptual model whose ergodicity would allow the description of the most disparate architectural morphological varieties. We also focus on the compactness of the descriptor in order to speed up the description process. At the façade level, for example, a descriptor to list the number of spans and floors is certainly decisive, as long as it does not encounter alignment breaks in the promising elements.

This effect is very visible in the historic district of the City of Lyon in that we are witnessing a radicalisation of the historically very localised building system: where before the span was carried out between two wall slits perpendicular to the street - with consequently a greater freedom of arrangement of the windows of the street front, from the 16th century onwards the load-bearing walls became the walls facing the street, with the need to respect the constraints linked to the lowering of loads materialising by a strict superposition of the openings made in the façade. Particular importance is given to the research of the smallest morphological polytope, a study of which has already been carried out and presented in more detail below. It is thus considered that any architectural form can be decomposed - or factorised - to its simplest expression, and that it can then, by simple geometric transformations (duplication by translation, scale or rotation) be used to produce complex formal combinations (Saleri et al. 2008). For example, a previous study focused on quickly describing an architectural object by providing predefined fields that allow the constituent characteristics of architectural elements to be approximated as closely as possible according to the three projection planes: the façade, the section and the plane.

Based on rules, these models aim to approach the external aspect of the models they generate, their constructive similarity and their historical and geographical proximity guarantee the limits in the 
morpho-style differences characterizing them; the underlying description model will include a reasonably limited set of descriptors, sufficient to discriminate against most formal disparities for a given family of objects. In this way, when faced with a historically coherent fabric, it is relatively easy to produce a credible disparity through a limited screen of parameters: for this "banal" architecture, representing an overwhelming majority of the architectural corpus to be described, a dozen simple rules will suffice. When power or social or religious representation so require, the means at stake make it possible to develop the response to the programmatic constraints of the commission by producing objects whose description would greatly exceed the descriptive capacities of the previously defined conceptual model: it would then be necessary to multiply the descriptive rules to approach the reality of a constructed object whose architectural singularity would in the worst case require a single set of rules per building, which would of course be counterproductive.

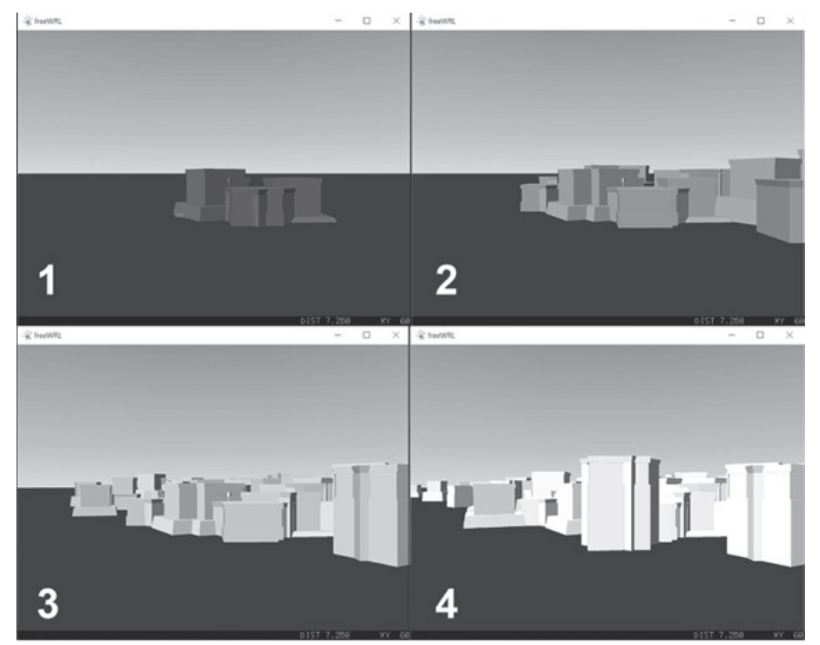

Figure 3: The L-System generator modelling a pseudo urban growing system.

Older works have explored the way to express in a more structured way the geometry of historic buildings through a recursive enumeration of its constituent elements: for example, they use Lsystem formalisms that make it possible to model in space and time less linear growth phenomena that are closer, we believe, to the growth dynamics that we encounter in reality, particularly in the field of living things. Their recursive and auto-similar properties will allow them to be displayed either with incremental levels of detail that can be a function of the distance from the observer to the object, or to produce evolutionary shapes that model, for example, the transformation of a built ensemble over time (Figure 3). Usually used to model plant growth, L-systems are based on axioms and rules mechanisms whose formal expression is easily applicable to constructed elements whose often redundant and self-mimetic character responds in reality to a need to simplify manufacturing processes: they are very well suited to recursive decomposition. Experience shows that the structuring of the variables used and the set of geometric transformations applied make it an extremely efficient $2 \mathrm{D}$ and $3 \mathrm{D}$ generator. The notion of "rewriting" makes it possible to carry out recursive affine transformations on a basic form or on each of its geometric components. Applied to topological rudiments specific to architecture, an infinite number of formal varieties can be obtained. Like Kasimir Malevich's architectones, they will show credible architectural or urban alternatives. Ongoing experiments are intended to demonstrate the formal versatility of this model in the service of the most disparate morphostylistic varieties (Parish and Müller 2001; Wonka et al. 2003; Jabi 2013).

\section{THE CASE STUDY OF CLAUDIUS AND TRAJAN PORT NEAR OSTIA}

The approach adopted concerns the establishment of historically plausible elements, in the light of current knowledge of the vernacular habitat of the Claudian and Trajane period. Few physical elements have survived to date, but the geographical proximity of the Ostia Archaeological Park, remarkably well preserved in elevation, gives a fairly accurate picture of the exterior appearance and construction techniques in vogue during the Roman period. Pompei and Herculaneum, dramatically well preserved despite the cataclysmic event that caused their loss, allow through the ages a rather precise vision of the construction methods implemented during the ancient period. The scientific literature is full of works that put in images the living environment in Roman times and, to a lesser extent, the world of comics clearly contributes to the creation of a widely shared collective imagination. On the other hand, largescale restitution requires an extremely rigorous use of available knowledge, which is eminently crosspollinating in that it often has to combine available data in the fields of urban planning, architecture, topography, hydrography, all of which may have passed through the ages in a more than chaotic manner. Jean Claude Golvin's watercolours, which have certainly questioned in depth the reasoned highlighting of unequally documented knowledge, pertinently juxtapose the most well-known elements (excavated, documented, published...) with the hypotheses of an urban fabric organised according to established rules but whose reality is often more speculative than established in a scientifically attested way. 


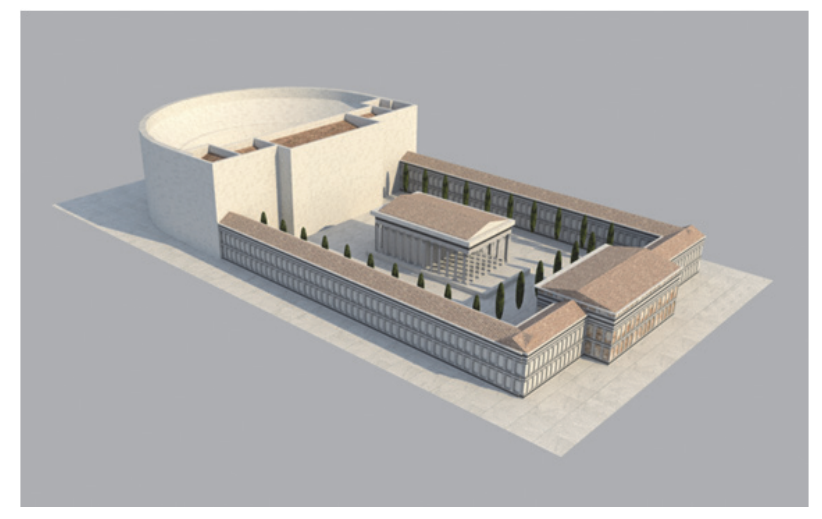

Figure 4: The Ostia's Theatre landmark, made of specific architectural primitives.

The "landmarks" (Figure 4) that punctuate the built space of the time - probably surviving thanks to a form of fearful benevolence towards structures related to power, institution, faith or public life constitute as many localised support points for the actual restitution work, to which the physical buds of the ancient urbs will be attached, which will lean against the visible or documented remains of the ancient traces.

The restitution work will thus be based on all the knowledge acquired at a given moment. They will depend on the progress of the excavation work or documentary research carried out. They can be very heterogeneous within the same site, which could compromise the validity of a $3 \mathrm{D}$ restitution locally. The destination of an area can also be extremely global, so it will be a matter of having the tools to partition the parcel, taking into account the dimensional rules commonly used at the time of interest. During the first experiments we started from a standard insula grid composed of 3 parallel modules of $85 \times 35 \mathrm{~m}$, themselves partitioned into four independent islands. For the purposes of the PORTUS project presented in this article, we have consolidated a pipeline that has already been partially tested during previous work. The software core is developed in JAVA and uses the findContours class implemented in the openCV library under Processing. It interprets the data from an appended text file that lists all the parameters used when detecting contours and creating architectural geometries. The MEL flow generated by the application is then sent via the localhost to Maya ${ }^{\circledR}$ which interprets the received data and invokes the shaders and textures assigned on the fly to the generated shapes (Figure 5).

The island stand parameters allow a street width of between 4 and $6 \mathrm{~m}$ and a building depth of between 5 and 10 meters. The 8 meters wide quotient (distance between buildings) finally allows a slight overlap of the built elements in order to break the excessive regularity that could result from an overly rigorous layout. The setback, on the other hand, is equal to 0 , which will produce a rigorous alignment of all the buildings on the street. Greater freedom is allowed in height, which will result in greater visual variety. The reconstruction is carried out starting from the façade elements, which will be broken down into structurally distinct entities: the masonry, the structural elements and the bays. This decomposition is based on a layering of the 3D support in the form of concentric enclosing boxes, generated on the fly in Maya $\AA$ in order to multiply the resulting combinations (Figure 6).
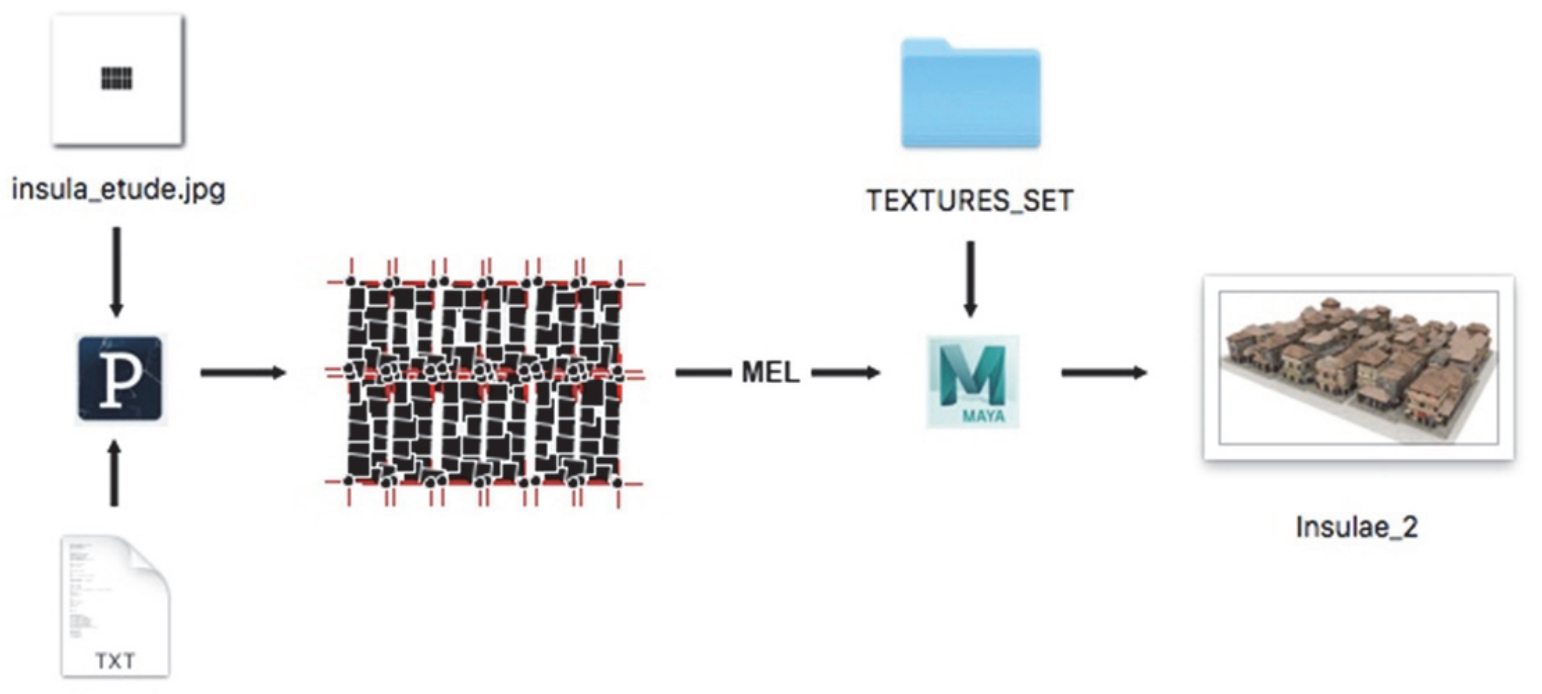

text_interface.txt

Figure 5: A FindEdges routine within a CV library extracting significant contours of a typical Insulae configuration (approx. $80 \times 35 \mathrm{~m})$. 


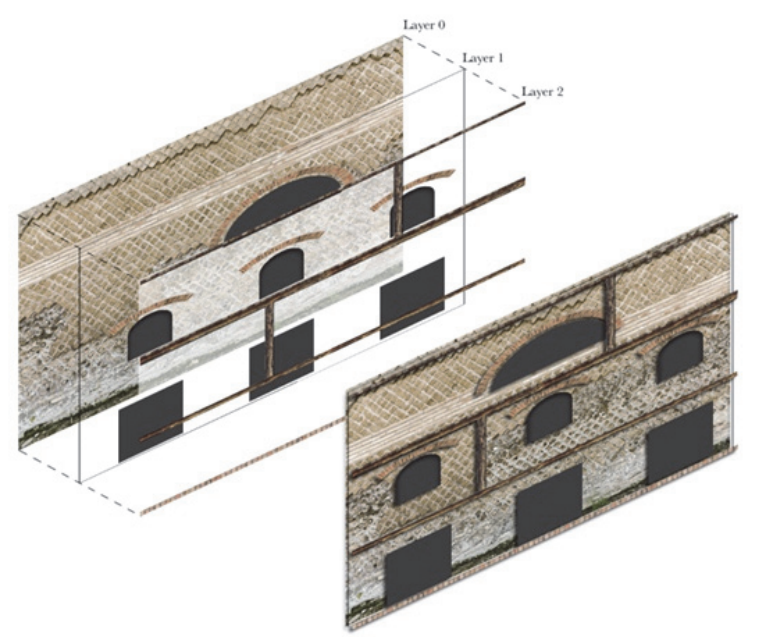

Figure 6: The façade system: the masonry layer, the embedded window transparency and colour layer and the structure layer.

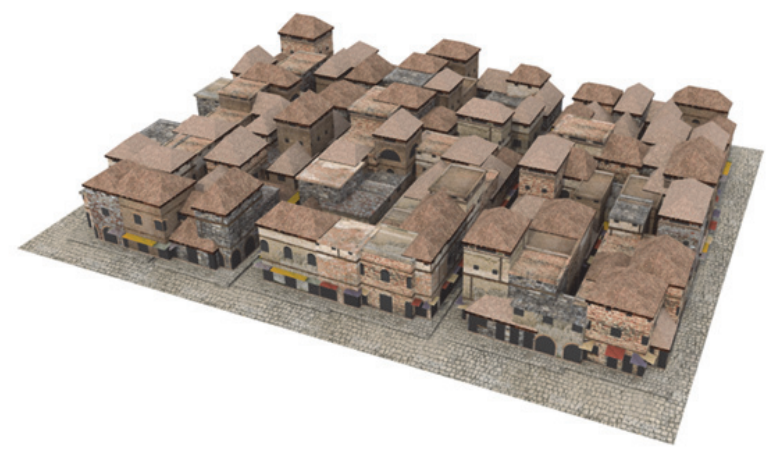

Figure 7: The resulting geometry.

The constituent layers of the façade elements are pre-composed separately and manufactured on request with a small amount of composition configured in 2D, this will allow constituting an extensive corpus of 2D primitives and ready-made façades that will produce at the end of the process an ever renewed visual variety. Another generative model fills the island in a more global way, it will be intended for denser urban areas for which the ratio of built area will concern the entire surface of the island. Finally, we have created a true modular digital construction system that has made it possible to meet the needs of detailed element construction, whether for boat garages or horrae, the suspended attics in which the grain was stored. For the moment there is no graphical interface and the data is defined through a text document, from which the information is extracted line by line.

Thus, in addition to the data concerning the dimensions (height, width, minimum and maximum number of floors), a withdrawal coefficient with respect to the roadway and a width quotient are defined which will define the spacing reserved over the perimeter devoted to the placement of the block in width. Then, if the possible width of the generated block exceeds the width quotient, the buildings may overlap transversely. The occupation of the island's depth is currently the subject of a more in-depth experiment that reinterprets the very way of producing the basic "block" entity (Figure 7).

Finally, following a series of studies already published, the operational principles of a generator developed a few years ago, which counted a very limited number of basic forms that could be mobilised during the generation of a type of vernacular habitat of the former urban fabric of Lyon, have also being put to the test. We list 4 basic plan configurations (single, double, convex and concave) whose geometric expression is multiplied by the 8 possible standard shapes for roofs. Finally, the façade descriptor completes the system and makes it possible to fill in the fields "basement, mezzanine, current floor and attic floor" for which it will be possible to count the number of floors, the number of spans being of course common. 

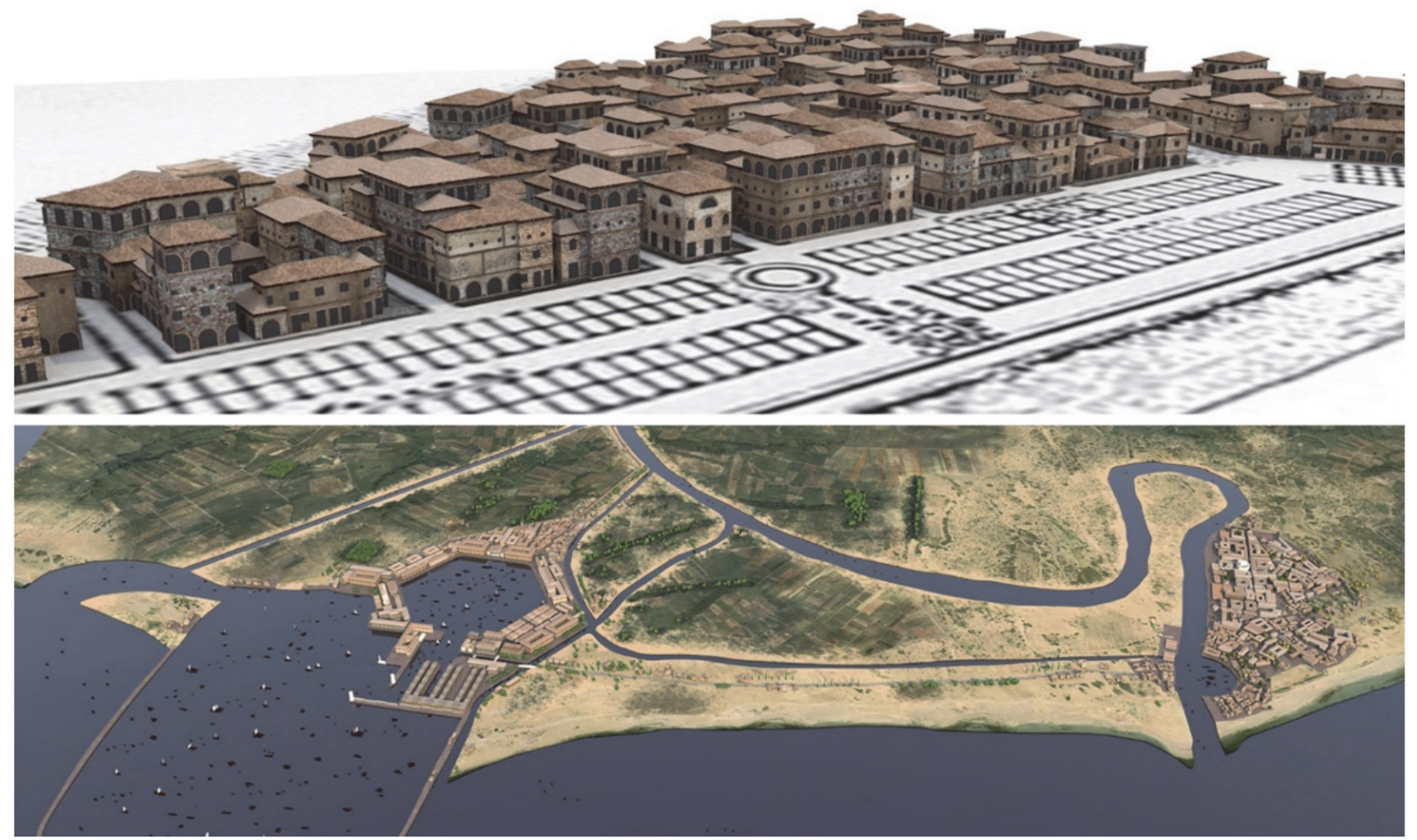

Figure 8: On top: positioning of the generated elements on the background map. Below: The generated elements integrated in the 3D restitution of Portus (left) and Ostia (right). (c) LUGDUNUM Musée et théatres romains - Musée des beaux arts de Lyon - Ecole Française de Rome - laboratoire MAP-aria.

\section{RESULTS AND PERSPECTIVES}

The research carried out restores two distinct states of the city of Ostia and Portus; it materialises the aspect of the port area under Emperor Claudius and shows the massive transformations brought by Emperor Trajan. The modelling of these two distinct periods led to questions throughout the study about the validity of the knowledge acquired, corroborated by the on-going contributions of the Ecole Française de Rome, which is still very active in this sector. The delimitation of the sectors concerned by the successive transformations of the parcel and the building is not definitively established and there remain vast areas for which dense urbanization at the period of interest to us is more than hypothetical; the very route of the coast is also questionable because the entire perimeter has not been excavated. The laboratory has thus implemented a set of measures to make the tools and documents implemented during the restitution campaign accessible by standardizing the file formats, simplifying the data structures used and making them - as far as possible - editable and updatable. All unused files were cleaned and all transformation and maintenance operations were carefully documented. Of course, we cannot foresee the arrival of a technology that will fundamentally challenge the operational practices that are now consolidated in the field of knowledge translation and dissemination. However, we believe that digital and smart collaborative support for excavation operations could enrich the overall operational maintenance and somehow guarantee the consistency of conservation protocols over time.

\section{REFERENCES}

Chevrier, C. (2015) Semiautomatic Parametric Modelling of the Buildings on Town Scale Models. Journal on Computing and Cultural Heritage 7, 120. https://doi.org/10.1145/2622609

Chevrier, C., Jacquot, K., Humbert, P., Ben Bouheni, S. and Halin, G. (2015) Virtual 3D reconstruction of Plan-Relief from historical document analysis for valorisation applications, in: 2015 Digital Heritage. Presented at the 2015 Digital Heritage, IEEE, Granada, Spain, pp.87-90. https://doi.org/10.1109/DigitalHeritage.2015.74138 $\underline{41}$

Duarte, J. (2001) Customizing mass housing: a discursive grammar for Siza's Malagueira houses. Massachusetts Institute of Technology. Dept. of Architecture, USA. 
Fons, E., Janda, M., Kiesgen, R. and Saleri, R., (2009) City blocs design with the aid of interactive evolutionary computation. The URBAG project background, in: 2009 International Conference on Computers \& Industrial Engineering. Presented at the Industrial Engineering (CIE39), IEEE, Troyes, France, pp.1712-1715.

https://doi.org/10.1109/ICCIE.2009.5223590

Gros, A., Jacquot, K. and Messaoudi, T. (2019) Knowledge-Based Framework for Automatic Semantisation and Reconstruction of Military Architecture on City-Scale Models. ISPRS International Archives of the Photogrammetry, Remote Sensing and Spatial Information Sciences XLII-2/W9, 369-375. https://doi.org/10.5194/isprsarchives-XLII-2-W9-369-2019

Haegler, S., Müller, P., and Van Gool, L. (2009) Procedural Modeling for Digital Cultural Heritage. EURASIP Journal on Image and Video Processing 2009, 1-11. https://doi.org/10.1155/2009/852392

Jabi, W. (2013) Parametric design for architecture. Laurence King, London.

Jacquot, K., Chevrier, C. and Halin, G. (2013) Reverse engineering of scale models using dataflow programming: Application to the fortification of plans-reliefs, in: 2013 Digital Heritage International Congress (DigitalHeritage). Presented at the 2013 Digital Heritage International Congress (DigitalHeritage), IEEE, Marseille, France, pp.6369.

https://doi.org/10.1109/DigitalHeritage.2013.67437 14

Marin, P., Marsault, X., Saleri, R., Duchanois, G., and Bignon, J.-C., (2012) L'Eco-Conception Générative: Une illustration de la pensée complexe, in: SCAN 2012: Actes du 5ème Séminaire de Conception Architecturale Numérique. PUN - Presses Universitaires de Lorraine.

Müller, P., Wonka, P., Haegler, S., Ulmer, A., and Van Gool, L. (2006) Procedural modeling of buildings. ACM Transactions on Graphics 25, 614. https://doi.org/10.1145/1141911.1141931

Müller, P., Zeng, G., Wonka, P., and Van Gool, L., (2007) Image-based procedural modeling of facades, in: ACM SIGGRAPH 2007 Papers on SIGGRAPH '07. Presented at the ACM SIGGRAPH 2007 papers, ACM Press, San Diego, California, p.85.

https://doi.org/10.1145/1275808.1276484

Parish, Y. I. H., Müller, P. (2001) Procedural modeling of cities, in: Proceedings of the 28th Annual Conference on Computer Graphics and Interactive Techniques -SIGGRAPH '01. Presented at the the 28th annual conference, ACM Press, Not Known, pp.301-308. https://doi.org/10.1145/383259.383292

Saleri, R. (2008) Urban and Architectural 3-D Fast Processing, in: Reflexing Interfaces: The Complex Coevolution of Information Technology Ecosystems. Information Science Reference, Hershey, PA, pp.278-289.

Saleri, R. (2004) Génération automatique de morphologies architecturales et urbaines. Presented at the Architectures, Urbanisme et Géometries.

Saleri, R. (2003) Pseudo-Urban automatic pattern generation, in: Proceedings of Generative Art 2002. Presented at the Generative Art 2002: 5th International Generative Art Conference, Milan, Italy, pp.24.1-24.12.

Saleri, R., Orsucci, F., and Sala, N. (2008) Automatic Processing of architectural and Urban Artifacts, in: Reflexing Interfaces: The Complex Coevolution of Information Technology Ecosystems. Orsucci F. End Sala N. Editors. IGI Group. Hershey, PA. Information Science Reference, Hershey, Pa.

Schinko, C., Strobl, M., Ullrich, T., and Fellner, D.W. (2010) Modeling Procedural Knowledge: A Generative Modeler for Cultural Heritage, in: loannides, M., Fellner, D., Georgopoulos, A., Hadjimitsis, D.G. (Eds.), Digital Heritage. Springer Berlin Heidelberg, Berlin, Heidelberg, pp.153-165. https://doi.org/10.1007/978-3-642-16873-4 12

Wonka, P., Wimmer, M., Sillion, F. and Ribarsky, W. (2003) Instant architecture. ACM Transactions on Graphics 22, 669.

https://doi.org/10.1145/882262.882324 